\title{
Germinoma With Syncytiotrophoblastic Giant Cells Arising in the Corpus Callosum
}

\author{
-Case Report-
}

\author{
Hajime YoneZawa, Yoshinari SHINSATO, Soichi ObaRa, Tatsuki OYOSHI, \\ Hirofumi HIRANO, Shinichi KITAJIMA*, and Kazunori ARITA
}

Department of Neurosurgery; and *Department of Human Pathology, Field of Oncology;

Graduate School of Medical and Dental Sciences, Kagoshima University, Kagoshima

\begin{abstract}
A previously healthy 31-year-old Japanese man presented with a very rare germinoma of the corpus callosum without other intracranial lesions manifesting as transitory speech disturbance. Magnetic resonance (MR) imaging revealed a heterogeneously enhanced mass in the corpus callosum extending into the cavity of the septum pellucidum. A tumor specimen obtained by stereotactic biopsy revealed a two-cell pattern germinoma containing human chorionic gonadotropin (HCG)- $\beta$-positive giant cells. The cerebrospinal fluid and serum levels of HCG and HCG- $\beta$ subunit were measurable. The diagnosis was germinoma with syncytiotrophoblastic giant cells. Three cycles of chemotherapy consisting of ifosfamide, cisplatin, and etoposide, followed by radiation therapy achieved complete remission, and 5 cycles of chemotherapy with carboplatin and etoposide were added. MR imaging performed 40 months after the diagnosis showed a cicatricial cyst in the body of the corpus callosum, the original tumor site. All 11 previously reported cases of germinoma in the corpus callosum were associated with synchronous or metachronous intracranial lesions. These patients tended to be older than patients with general intracranial germinoma. Germinoma should be included in the differential diagnosis of corpus callosum tumors, especially in young adult males.
\end{abstract}

Key words: germinoma with syncytiotrophoblastic giant cells, germ cell tumor, corpus callosum, ectopic germinoma, human chorionic gonadotropin

\section{Introduction}

Intracranial germinomas preferentially arise in the pineal or neurohypophyseal regions, ${ }^{9,11)}$ whereas only $5-10 \%$ develop in other brain regions, which are known as "ectopic germinomas." Germinomas in the basal ganglia and thalamus are quite common, ${ }^{8)}$ but are rarer in the corona radiata, ${ }^{13)}$ temporal lobe, ${ }^{20)}$ posterior cranial fossa, ${ }^{4,11)}$ medulla oblongata, ${ }^{22)}$ cerebellum, ${ }^{11,12)}$ pituitary fossa, ${ }^{2)}$ optic chiasm, ${ }^{21)}$ and intramedullary spinal cord ${ }^{5)}$ Ectopic germinomas may result from mismigration of embryonic cells into the neural plate area, so the midline of the embryonic disk is a site of germ cell tumor origin. ${ }^{14)}$ Therefore, these tumors may originate from any midline structure of the central nervous system. Germ cell tumors including germinomas in the corpus callosum are very rare and are usually associated with other intracranial lesions. , $^{1,9,9,11,16-20)}$ Only one of 153 germ cell tumors was located in the corpus callosum (0.7\%). ${ }^{11)}$ The reason for the low incidence of germ cell tumors arising at the corpus callosum is unclear, but may be related to the pathogenesis of intracranial germ cell tumors. Mismigration of proliferating embryon-

Received October 22, 2009; Accepted January 6, 2010 ic disk cells may precede the formation of the corpus callosum, which occurs in the $12^{\text {th }}$ to $13^{\text {th }}$ week of embryogenesis.

We report a case of primary corpus callosum germinoma without other intracranial lesions.

\section{Case Report}

A 31-year-old Japanese man noticed sudden onset of speech disturbance lasting a few minutes followed by transient numbness in the fingers of the right hand. Computed tomography of the brain obtained 2 days after the event demonstrated a mass in the corpus callosum. Magnetic resonance (MR) imaging revealed a heterogeneously enhanced mass measuring $40 \mathrm{~mm}$ in maximum diameter, located in the body of the corpus callosum and extending into the cavity of the septum pellucidum. No other intracranial lesions were identified (Fig. 1).

Stereotactic biopsy was performed. Histological examination revealed a two-cell pattern consisting of sheets of large tumor cells and infiltrating small lymphocytes. The large tumor cells had round vesicular nuclei with prominent nucleoli and abundant clear cytoplasm. Immunohistochemical staining was positive for placental alkaline 

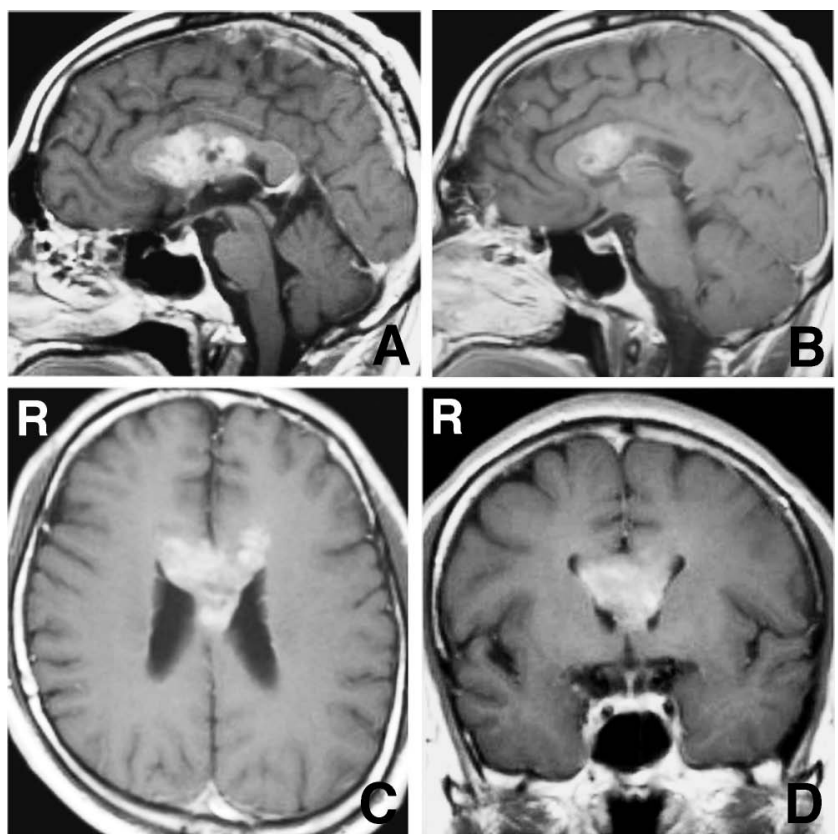

Fig. 1 Preoperative midsagittal (A), sagittal (B, $5 \mathrm{~mm}$ to right of center), axial (C), and coronal (D) $T_{1}$-weighted magnetic resonance images with gadolinium showing a heterogeneously enhanced tumor located in the corpus callosum with extension into the cavity of the septum pellucidum, but no other lesions.

phosphatase and c-kit (Fig. 2A-C). Giant cells scattered in the tumor were positive for human chorionic gonadotropin (HCG)- $\beta$ (Fig. 2D). The diagnosis was germinoma with syncytiotrophoblastic giant cells (STGC). The serum and cerebrospinal fluid (CSF) titers were 17 and 71 $\mathrm{mIU} / \mathrm{ml}$ for HCG, and 0.2 and $1.5 \mathrm{ng} / \mathrm{ml}$ for HCG- $\beta$ subunit, respectively. The serum titer of alpha-fetoprotein was within normal limits $(1.7 \mathrm{ng} / \mathrm{ml})$, and the CSF titer was below detectability.

Chemotherapy consisting of ifosfamide, cisplatin, and etoposide (ICE) ${ }^{10)}$ was started. The tumor had completely disappeared after the second cycle of ICE therapy (Fig. $3 \mathrm{~A}$ ). MR imaging showed a cystic lesion in the body of the corpus callosum. The serum levels of HCG and HCG- $\beta$ subunit fell below the level of detectability. Radiation therapy was then begun consisting of multi-fractionated $30 \mathrm{~Gy}$ of extended local irradiation covering the whole ventricular system followed by $20 \mathrm{~Gy}$ of boost irradiation to the initial tumor site. Subsequently, he received another cycle of ICE therapy and 5 cycles of a chemotherapeutic regimen consisting of carboplatin and etoposide (CARB-VP). ${ }^{10)}$ The entire treatment course was completed by 17 months after the onset. The latest follow-up MR imaging, 24 months after the completion of treatment and 40 months after the diagnosis, showed no tumor recurrence or dissemination. The cicatricial cyst in the corpus callosum, the original tumor site, persisted and the callosal body showed topical atrophy (Fig. 3B).

There were no signs and symptoms of hypopituitarism or diabetes insipidus throughout the clinical course. The basal levels of thyroid-stimulating hormone, cortisol,

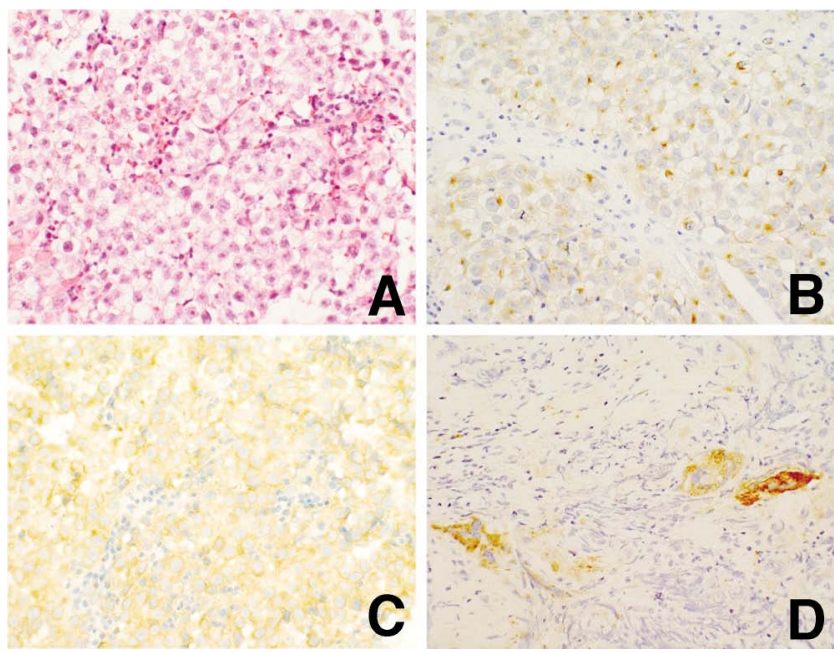

Fig. 2 A: Photomicrograph showing the tumor tissues consisting of 2 distinct cell types: large round cells with clear cytoplasm and central nuclei, and small lymphocytes infiltrating fibrous tissue. Hematoxylin and eosin stain, $\times 200$. B-D: Immunostaining showing the large round cells are positive for placental alkaline phosphatase (B) and c-kit (C), and scattered giant cells are positive for human chorionic gonadotropin- $\beta$ (D). $\times 200$.
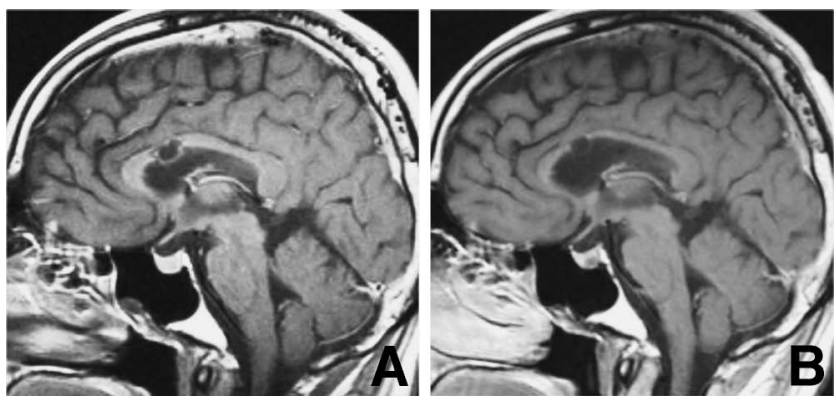

Fig. 3 Sagittal $T_{1}$-weighted magnetic resonance images with gadolinium after the second cycle of chemotherapy (A), and 24 months after completion of treatment (B), showing the callosal lesion has completely disappeared and a cicatricial cyst is present in the body of the corpus callosum $(\mathrm{A}, \mathrm{B})$, and atrophy of the corpus callosum (B).

prolactin, and adrenocorticotropic hormone remained within the normal ranges, and were $0.72 \mu \mathrm{IU} / \mathrm{ml}, 9.6 \mu \mathrm{g} / \mathrm{dl}$, $7.1 \mathrm{ng} / \mathrm{ml}$, and $10.1 \mathrm{pg} / \mathrm{ml}$, respectively, at the end point of treatment.

\section{Discussion}

Preoperative MR imaging of our patient showed an intracranial lesion in the corpus callosum that extended to the cavity of the septum pellucidum. MR imaging performed after chemoradiation therapy revealed a cicatricial cyst associated with surrounding atrophy in the body of the corpus callosum. We conclude that this tumor arose and grew in the corpus callosum, a very rare origin for 
Table 1 Reported cases of germ cell tumors in the corpus callosum

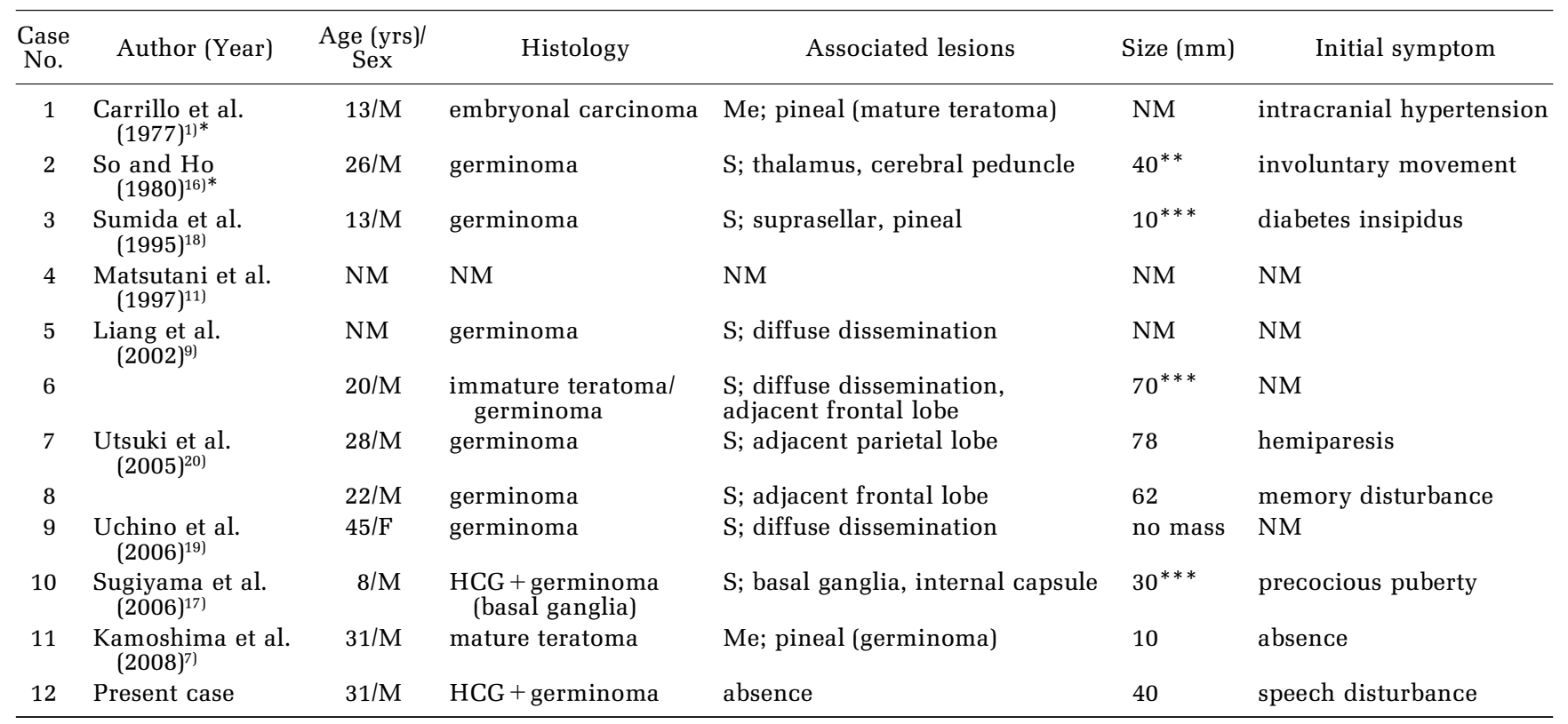

${ }^{*}$ Magnetic resonance imaging was not performed. ${ }^{* *}$ Removed specimen size. ${ }^{* * *}$ Estimated from the published figure. HCG: human chorionic gonadotropin, Me: metachronous lesions, NM: not mentioned, S: synchronous lesions.

intracranial germ cell tumors. Only 11 patients with germ cell tumors in the corpus callosum have been reported,,$^{1,7,9,11,16-20)}$ all associated other intracranial lesions including disseminated periventricular tumors, adjacent cerebral parenchymal lesions, and so-called favorite site lesions (Table 1). Patients with corpus callosum germ cell tumors tended to be older (mean \pm standard deviation [SD] $23.7 \pm 10.9$ years) than patients with more common intracranial germinomas. ${ }^{6,10,15)}$ The initial symptoms included intracranial hypertension, involuntary movement, memory disturbance, and symptoms related to the associated lesions. The symptoms elicited by callosal tumors are relatively mild considering their large size (mean \pm SD $50.0 \pm 25.0 \mathrm{~mm}$ ). We think that such lesions developed without eliciting conspicuous symptoms because the corpus callosum is a relatively non-eloquent brain structure. ${ }^{20)}$

The histological diagnosis in our case was germinoma with STGC or HCG-producing germinoma. Intracranial germinomas with STGC account for $12.6-18.9 \%$ of all intracranial germinomas. ${ }^{11,15)}$ The prognosis for patients with germinoma containing STGC is not as good as that for patients with pure germinoma due to the high rate of recurrence. ${ }^{11,15)}$ The 5-year survival rate of 7 patients with germinoma with STGC was as low as $83.3 \%$ compared to 95.4\% in 50 patients with pure germinoma. ${ }^{11)}$ Analysis of 111 germ cell tumors, including 60 pure and 14 HCGproducing germinomas, found the recurrence rate of HCG-producing germinomas was higher than that of pure germinomas. ${ }^{15)}$ According to the treatment protocol for intracranial germ cell tumors, ${ }^{10)}$ HCG-producing germinomas are in the intermediate prognosis group. In our case, 3 cycles of ICE therapy combined with extended local and local boost irradiation were delivered followed by 5 cycles of a CARB-VP regimen, resulting in complete response in our patient. He remained in good condition with no signs of recurrence at 24 months after the completion of treatment. Longitudinal regular follow-up MR imaging continues because germinomas with STGC tend to recur later than pure germinomas. ${ }^{3,15}$

\section{References}

1) Carrillo R, Ricoy JR, Del Pozo JM, García-Uria J, Herrero J: Dissemination with malignant changes from a pineal tumor through the corpus callosum after total removal. Childs Brain 3: 230-237, 1977

2) Frank G, Galassi E, Fabrizi AP, Frank F, Manetto V: Primary intrasellar germinoma: Case report. Neurosurgery 30: 786-788, 1992

3) Fujikawa K, Kawahara Y, Hirano H, Yokoyama S, Niiro M, Kuratsu J: Germinoma with syncytiotrophoblastic giant cells recurring 13 years after radiotherapy for a pineal germinoma-case report. Neurol Med Chir (Tokyo) 43: 146-149, 2003

4) Fujiwara K, Uenohara H, Suzuki H, Sakurai Y: Intracranial germinoma with syncytiotrophoblastic giant cells in the cerebellopontine angle-case report. Neurol Med Chir (Tokyo) 42: 132-136, 2002

5) Hata M, Ogino I, Sakata K, Murata H, Kawano N, Matsubara S: Intramedullary spinal cord germinoma: Case report and review of the literature. Radiology 223: 379-383, 2002

6) Jennings MT, Gelman R, Hochberg F: Intracranial germ-cell tumors: Natural history and pathogenesis. J Neurosurg 63: 155-167, 1985

7) Kamoshima Y, Sawamura Y, Iwasaki M, Iwasaki Y, Sugiyama K: Metachronous mature teratoma in the corpus callosum occurring 12 years after a pineal germinoma. $J$ Neu- 
rosurg 109: 126-129, 2008

8) Kim DI, Yoon PH, Ryu YH, Jeon P, Hwang GJ: MRI of germinomas arising from the basal ganglia and thalamus. Neuroradiology 40: 507-511, 1998

9) Liang L, Korogi Y, Sugahara T, Ikushima I, Shigemitsu Y, Okuda T, Takahashi M, Kochi M, Ushio Y: MRI of intracranial germ-cell tumors. Neuroradiology 44: 382-388, 2002

10) Matsutani M; Japanese Pediatric Brain Tumor Study Group: Combined chemotherapy and radiation therapy for CNS germ cell tumors-the Japanese experience. J Neurooncol 54: 311-316, 2001

11) Matsutani M, Sano K, Takakura K, Fujimaki T, Nakamura O, Funata N, Seto T: Primary intracranial germ cell tumors: A clinical analysis of 153 histologically verified cases. J Neurosurg 86: 446-455, 1997

12) Nakase $H$, Ohnishi $H$, Touho $H$, Karasawa J, Tsunoda $S$ : Cerebellar primary germ-cell tumor in a young boy. Brain Dev 16: 396-398, 1994

13) Okuno S, Hisanaga M, Chitoku S, Sakaki T, Tsunoda S: [Germinoma with granulomatous reaction arising from the corona radiata; Case report and review of articles]. No Shinkei Geka 20: 775-780, 1992 (Japanese)

14) Sano K: Pathogenesis of intracranial germ cell tumors reconsidered. J Neurosurg 90: 258-264, 1999

15) Sawamura Y, Ikeda J, Shirato H, Tada M, Abe H: Germ cell tumours of the central nervous system: Treatment consideration based on 111 cases and their long-term clinical outcomes. Eur J Cancer 34: 104-110,1998

16) So SC, Ho J: Multiple primary germinomas (ectopic pinealo- ma) of the brain. Neurochirurgia (Stuttg) 23: 147-150, 1980

17) Sugiyama S, Kumabe T, Mino M, Fujimura M, Fujiwara I, Tominaga T: [Precocious puberty caused by hCG-producing germinoma involving the bilateral basal ganglia and cerebral white matter without typical radiologic findings: Case report]. No Shinkei Geka 34: 619-624, 2006 (Japanese)

18) Sumida M, Uozumi T, Kiya K, Mukada K, Arita K, Kurisu K, Sugiyama K, Onda J, Satoh H, Ikawa F, Migita K: MRI of intracranial germ cell tumours. Neuroradiology 37: 32-37, 1995

19) Uchino A, Takase Y, Nomiyama K, Egashira R, Kudo S: Acquired lesions of the corpus callosum: MR imaging. Eur Radiol 16: 905-914, 2006

20) Utsuki S, Oka H, Tanizaki Y, Kondou K, Fujii K: Radiological features of germinoma arising from atypical locations-three case reports. Neurol Med Chir (Tokyo) 45: 268-271, 2005

21) Wilson JT, Wald SL, Aitken PA, Mastromateo J, Vieco PT: Primary diffuse chiasmatic germinomas: Differentiation from optic chiasm gliomas. Pediatr Neurosurg 23: 1-6, 1995

22) Yen PS, Chou AS, Chen CJ, Jung SM, Chuang HL, Scotto RM: Primary medulla oblongata germinoma: A case report and review of the literature. J Neurooncol 62: 339-342, 2003

Address reprint requests to: Hajime Yonezawa, M.D., Department of Neurosurgery, Graduate School of Medical and Dental Sciences, Kagoshima University, 8-35-1 Sakuragaoka, Kagoshima 890-8520, Japan.

e-mail: hajime@m3.kufm.kagoshima-u.ac.jp 